\title{
Systematic review of time trends in the prevalence of Helicobacter pylori infection in China and the USA
}

Peter Nagy ${ }^{1 *}$, Saga Johansson ${ }^{1}$ and Michael Molloy-Bland ${ }^{2,3}$

\begin{abstract}
It has been suggested that the prevalence of Helicobacter pylori infection has stabilized in the USA and is decreasing in China. We conducted a systematic literature analysis to test this hypothesis. PubMed and Embase searches were conducted up to 19 January 2015. Trends in the prevalence of H. pylori infection over time were assessed by regression analysis using Microsoft Excel. Overall, 25 Chinese studies (contributing 28 datasets) and 11 US studies (contributing 11 datasets) were included. There was a significant decrease over time in the H. pylori infection prevalence for the Chinese studies overall $(p=0.00018)$ and when studies were limited to those that used serum immunoglobulin $G$ ( $\mathrm{lgG}$ assays to detect $H$. pylori infection ( $p=0.014 ; 20$ datasets). The weighted mean prevalence of $H$. pylori infection was $66 \%$ for rural Chinese populations and $47 \%$ for urban Chinese populations. There was a significant trend towards a decreasing prevalence of $H$. pylori infection for studies that included only urban populations ( $p=0.04 ; 9$ datasets). This trend was no longer statistically significant when these studies were further restricted to those that used serum IgG assays to detect H. pylori infection, although this may have been because of low statistical power due to the small number of datasets available for this analysis ( $p=0.28 ; 6$ datasets). There were no significant trends in terms of changes in the prevalence of $\mathrm{H}$. pylori infection over time for studies conducted in the USA. In conclusion, the prevalence of $H$. pylori infection is most likely decreasing in China, due to a combination of increasing urbanization, which we found to be associated with lower $\mathrm{H}$. pylori infection rates, and possibly also decreasing rates of $\mathrm{H}$. pylori infection within urban populations. This will probably result in a gradual decrease in peptic ulcer and gastric cancer rates in China over time.
\end{abstract}

Keywords: Helicobacter pylori, Prevalence, China, USA, Time trends

\section{Background}

Helicobacter pylori infection is well recognized as the main pathogenic factor for peptic ulcer disease and chronic gastritis, and in a subset of patients it is a major risk factor for gastric cancer and mucosa-associated lymphoid tissue lymphoma [1-3]. Helicobacter pylori infection has also been associated with increased risks of colon cancer [4], idiopathic thrombocytopenic purpura, iron deficiency anemia, vitamin $B_{12}$ deficiency, and, more recently, neurodegenerative disorders and metabolic syndrome [5]. Conversely, a reduced risk of developing

\footnotetext{
*Correspondence: peter.nagy@astrazeneca.com

${ }^{1}$ AstraZeneca Gothenburg, Pepparedsleden 1,431 83 Mölndal, Sweden Full list of author information is available at the end of the article
}

gastroesophageal reflux disease (GERD) with reflux esophagitis has been linked to infection with $H$. pylori (particularly in East Asia) [6-8], although this association remains controversial due to some conflicting results $[5$, 9-11].

Given the potential health consequences of $H$. pylori infection it is important to understand its prevalence in a population at any given time. Perhaps even more importantly from a healthcare planning perspective, it is useful to look at past trends in the prevalence of $H$. pylori infection so that its future prevalence and impact may be estimated. Infection with $H$. pylori is believed to be acquired mainly during childhood, remaining for the lifetime of the individual unless eradicated. In developed countries, mother-to-child transmission is 
the dominant mechanism; horizontal transmission is less likely than in developing countries because of better sanitation [12]. In developing countries, horizontal transmission may play a concomitant role with intrafamilial infection, leading to a higher prevalence. Consistent with these hypotheses, the prevalence of $H$. pylori has been greatly reduced over time in parallel with the westernization of Asian cultures such as Japan [13]. It is likely that the prevalence of $H$. pylori infection in China is decreasing too owing to improvements in living standards associated with recent rapid industrialization and urbanization.

Gastric cancer was the most common cancer in the first quarter of the 20th century. Since then, the incidence has decreased rapidly in the USA but has remained high in the Far East [14]. Despite the obvious health implications of changes in the prevalence of $H$. pylori infection, studies reporting prevalence data in China have not, to our knowledge, been systematically reviewed. We therefore systematically reviewed studies reporting the prevalence of $H$. pylori infection in Chinese adults, with a focus on trends over time. For comparison, we also systematically reviewed studies reporting the prevalence of $H$. pylori infection in adults in the USA.

\section{Methods}

\section{Systematic searches and study selection}

Systematic searches were conducted in PubMed and Embase (via Ovid SP) up to 19 January 2015. Filters were applied to limit the searches to studies conducted in humans and published in English. Studies were considered for inclusion in the review if they reported the general prevalence of $H$. pylori infection in adults in mainland China or the USA. Exclusion criteria were: sample size less than 100 participants; absence of information on the time period during which the study was conducted; and population selection bias that could significantly impact on the reported prevalence of $H$. pylori infection (e.g., based on ethnicity, income, presence of upper gastrointestinal diseases [peptic ulcer, gastric cancer], or symptoms). Samples deemed acceptable for inclusion in terms of having minimal selection bias included those from population-based or health-check studies and healthy controls from case-control studies. Owing to the relatively low number of suitable US studies identified, samples from cohorts of patients with diseases not established (to our knowledge) as being associated with higher or lower $H$. pylori infection rates were also included, although data from healthy controls in such studies were preferentially selected if available. A Preferred Reporting Items for Systematic Reviews and Meta-Analyses [15] flow diagram of the search strategy is presented in Fig. 1.

\section{Data analysis}

Prevalence data were plotted according to the midpoint of the study period (study midpoint). The study midpoint was defined as halfway (to the nearest 3 months) between the beginning and end of the reported study period. Trends in the prevalence of $H$. pylori infection over time were assessed by regression analysis using Microsoft Excel. In addition, because the trend analysis does not take into account the respective sample sizes of the contributing studies, Chinese and US studies were also grouped according to whether their study midpoint was before or after the mean of all study midpoints, and weighted mean prevalence estimates for $H$. pylori infection were calculated for these groups.

\section{Results}

Search results and study characteristics

Of 762 unique hits, 25 studies conducted in China [1640] and 10 conducted in the USA [41-50] were included in the analysis. The study by Zhang et al. (2009) [31] included data from two separate rural populations (Muping County [Shandong province] and Yanqing County [Beijing Municipality]) and thus contributed two separate datasets for the purpose of the analysis. The studies by Chen et al. (2003) [20] and Chen et al. (2007) [22] each included data at two distinct time points from a single urban population (Shanghai and Guangzhou city, respectively), and thus also contributed two datasets each to the analysis. Therefore, there were 28 datasets in the Chinese analysis overall, and 10 in the US analysis (i.e., one dataset from each US study).

Characteristics of the included datasets are presented in Table 1 for the Chinese studies and as supplementary material (Additional file 1: Table S1-online) for the US studies. The mean sample size was 1621 (range: 100-8820) for the Chinese datasets and 1742 (range: 143-7465) for the US datasets. The Chinese datasets came mainly (26/28 [93\%]) from general population or health-check studies, or from healthy controls in casecontrol studies; half $(5 / 10)$ of the US datasets came from these sources. Serum immunoglobulin G (IgG) assays were used to detect $H$. pylori infection in all of the US datasets, and in all Chinese datasets with study midpoints before the mean of all study midpoints for that country. There were variations, however, in the $H$. pylori detection methods used in the Chinese datasets with study midpoints after the mean of all Chinese study midpoints. In addition, a substantially higher proportion of datasets from Chinese studies conducted before the mean of the study midpoints were from rural (rather than urban) populations (8/12), compared with the proportion from studies conducted afterwards (3/16). Finally, although all included data were from adults, age distributions varied 
PubMed search string (adapted for use in Embase)

("Helicobacter pylori"[MeSH] OR "Helicobacter pylori"[title/abstract]) AND ("prevalence"[MeSH] OR "prevalence"[title/abstract]) AND ("United States"[MeSH] OR "USA"[title/abstract] OR "US"[title/abstract] OR "United States"[title/abstract] OR "America"[title/abstract] OR "China"[MeSH] OR "China"[title/abstract] OR "Chinese"[title/abstract])

Search period: up to 19 January 2015

Filters: Humans, English, Journal article, NOT reviews

PubMed searches $(n=392)$ and Embase searches $(n=541)$ combined and duplicates removed $n=762$

Studies excluded based on manual review of titles and/or abstracts $(n=621)$

General exclusion reasons: irrelevant study topic; study conducted in children; selection bias that could significantly affect estimated $H$. pylori infection prevalence; not conducted in mainland China or USA; duplicate reference; not a primary research article

\begin{tabular}{|c|}
\hline$n=141$ \\
\hline Studies excluded based on manual review of full-text articles $(n=106)$ \\
\hline \multirow{9}{*}{$\begin{array}{l}\text { Selection bias that could significantly affect } H \text {. pylori infection prevalence }(n=24) \\
\text { Used unconventional } H \text {. pylori detection method }(n=1) \\
\text { Did not recruit adults or did not report data separately for adults }(n=17) \\
\text { Did not report relevant } H \text {. pylori prevalence data }(n=6) \\
\text { Not conducted in mainland China or USA }(n=20) \\
\text { Duplicate article or study population }(n=16) \\
\text { Not a primary research article }(n=5) \\
\text { Study period not specified }(n=15) \\
N<100(n=2)\end{array}$} \\
\hline \\
\hline \\
\hline \\
\hline \\
\hline \\
\hline \\
\hline \\
\hline \\
\hline $\mathrm{n}=35$ \\
\hline $\begin{array}{l}\text { Included studies recruiting patients from USA }(n=10) \\
\text { Included studies recruiting patients from mainland China }(n=25)\end{array}$ \\
\hline
\end{tabular}

Fig. 1 Preferred Reporting Items for Systematic Reviews and Meta-Analyses (PRISMA) flow diagram of the search strategy

across both the Chinese and US datasets, as did the statistical measures used to report age characteristics. Datasets from US studies with a midpoint that was after the mean of all US study midpoints tended to include older patients than those from studies with a midpoint that was before the mean of the study midpoints. There were no clear differences in the age distributions of individuals in datasets from Chinese studies with study midpoints before versus after the mean of all study midpoints.

\section{H. pylori infection prevalence over time in China}

The weighted mean prevalence of $H$. pylori infection across all years was 55 \% (range: 28-82 \% [1983-2013]) for the Chinese datasets (Table 1). There was a significant decrease over time in the prevalence of $H$. pylori infection when all the Chinese datasets were included in the analysis ( $p=0.00018$; Fig. 2a). Consistent with this trend, the weighted mean prevalence of $H$. pylori infection was higher for Chinese datasets with study midpoints that fell before than for those with study midpoints that fell after the mean of all study midpoints (68 vs $48 \%$; Fig. 3 ).

The trend of decreasing prevalence of $H$. pylori infection over time remained when the analysis was limited to datasets that used serum IgG assays to detect $H$. pylori infection ( $p=0.014$; Fig. 2b). Similarly, the weighted mean prevalence of $H$. pylori infection was higher for datasets with midpoints that fell before, versus after, the mean of all study midpoints (69 vs 56 \%; Fig. 3). 


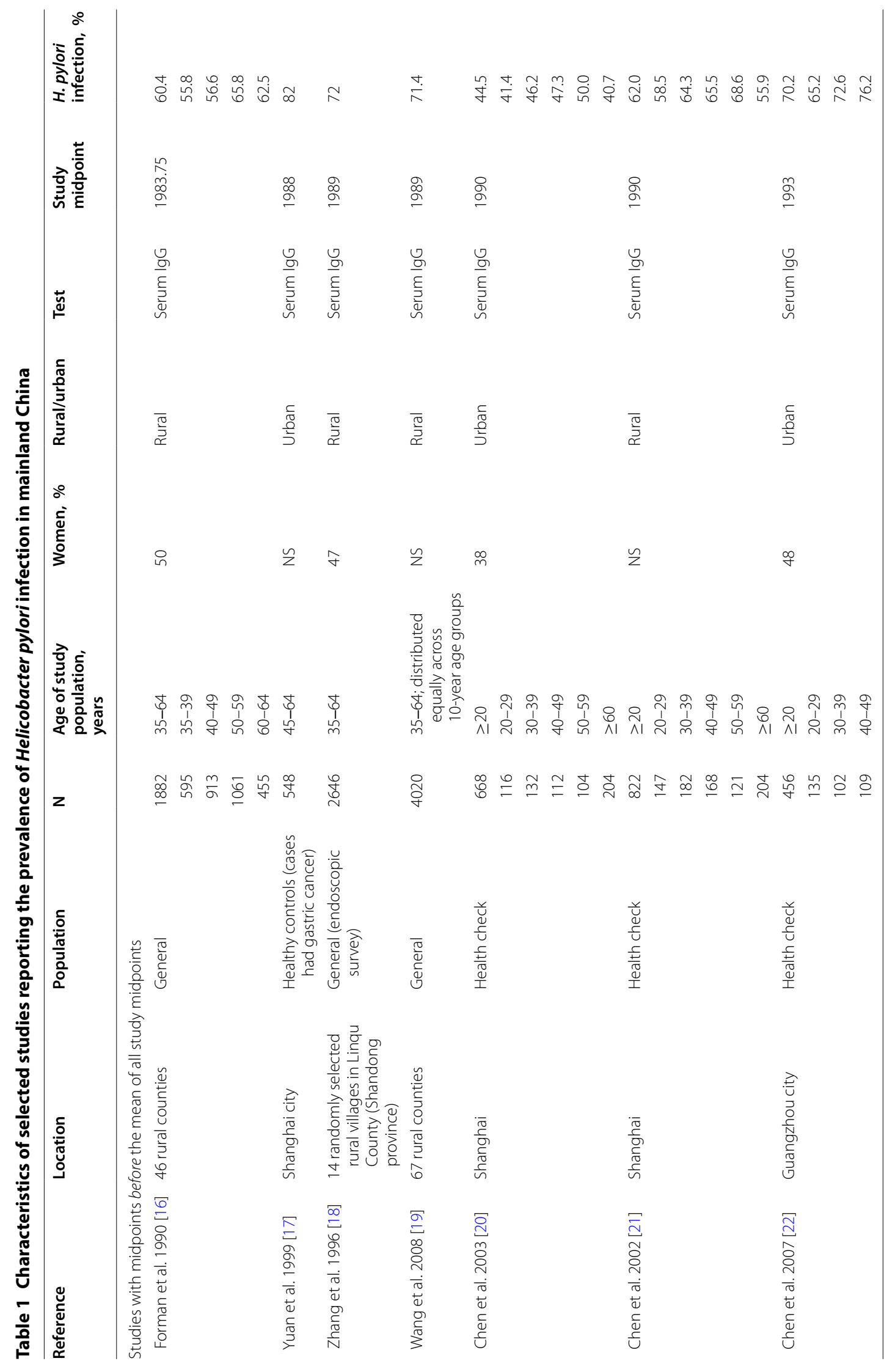




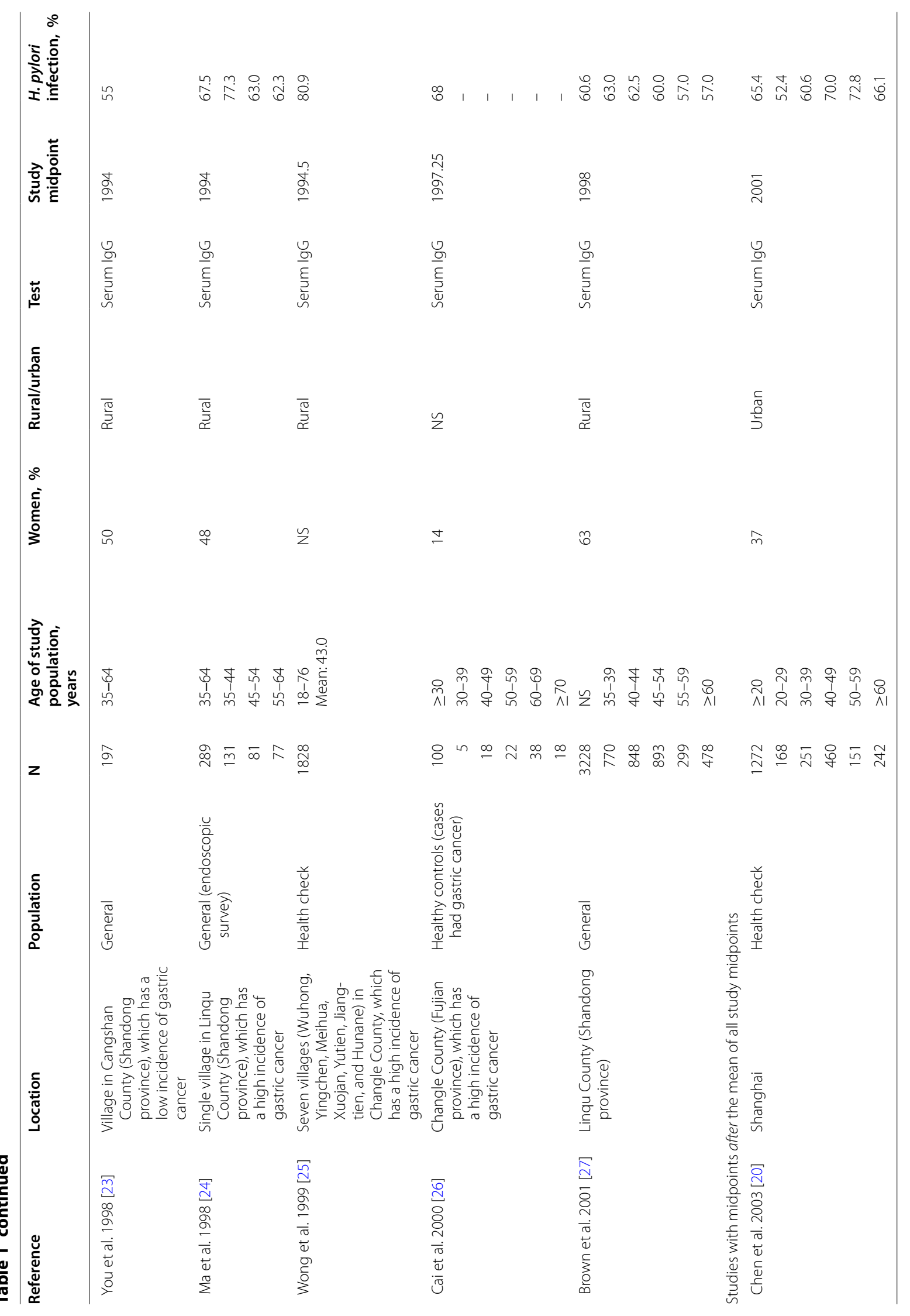




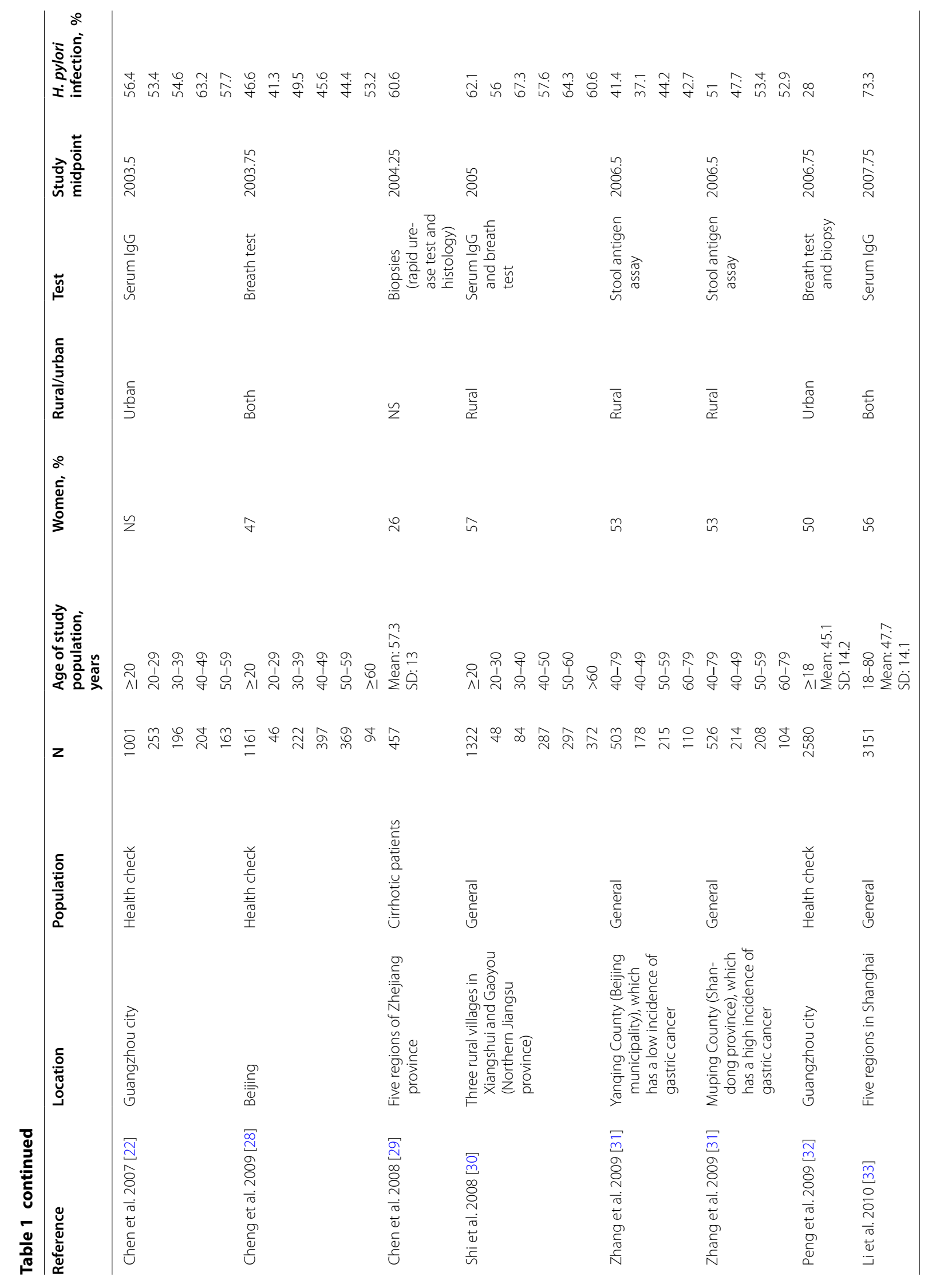




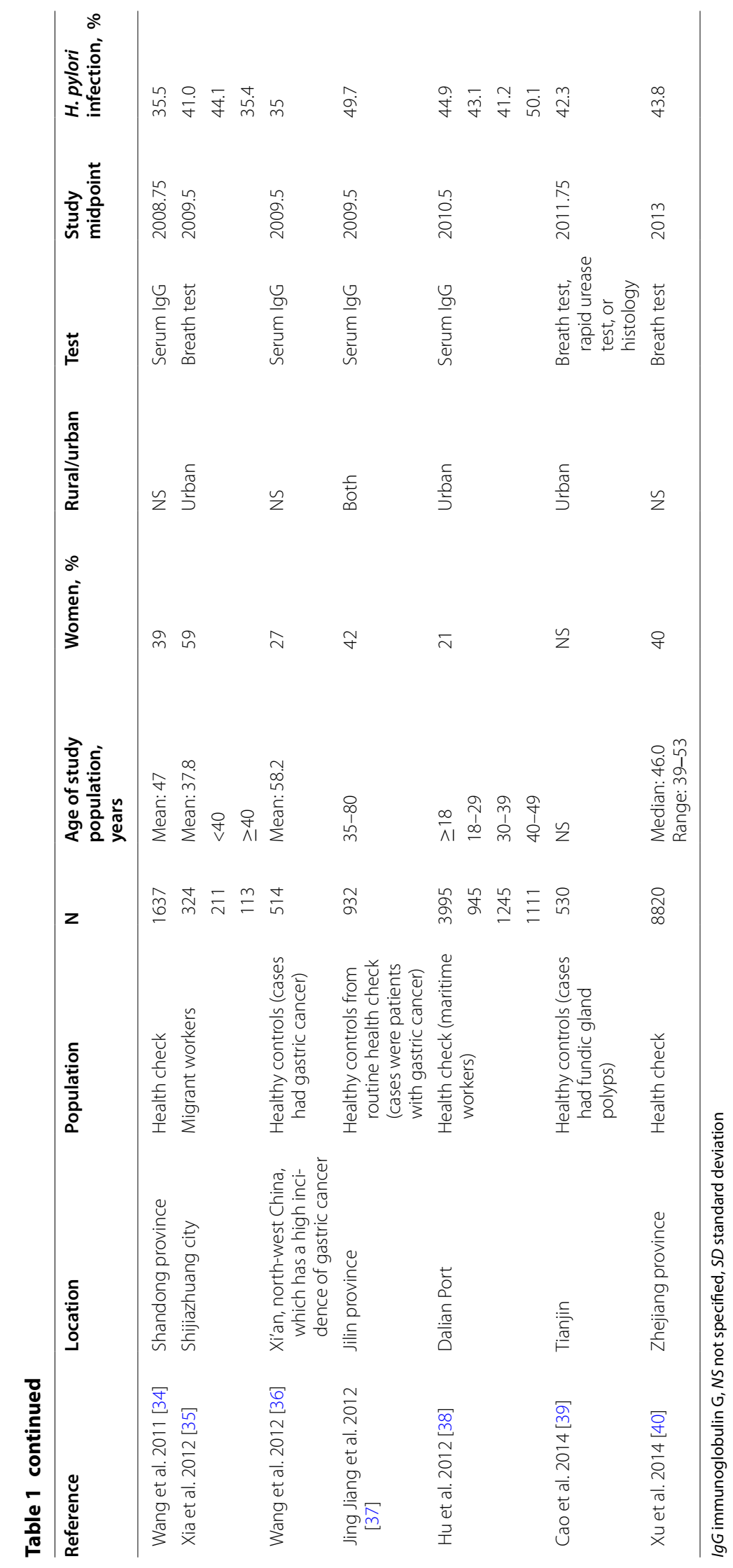




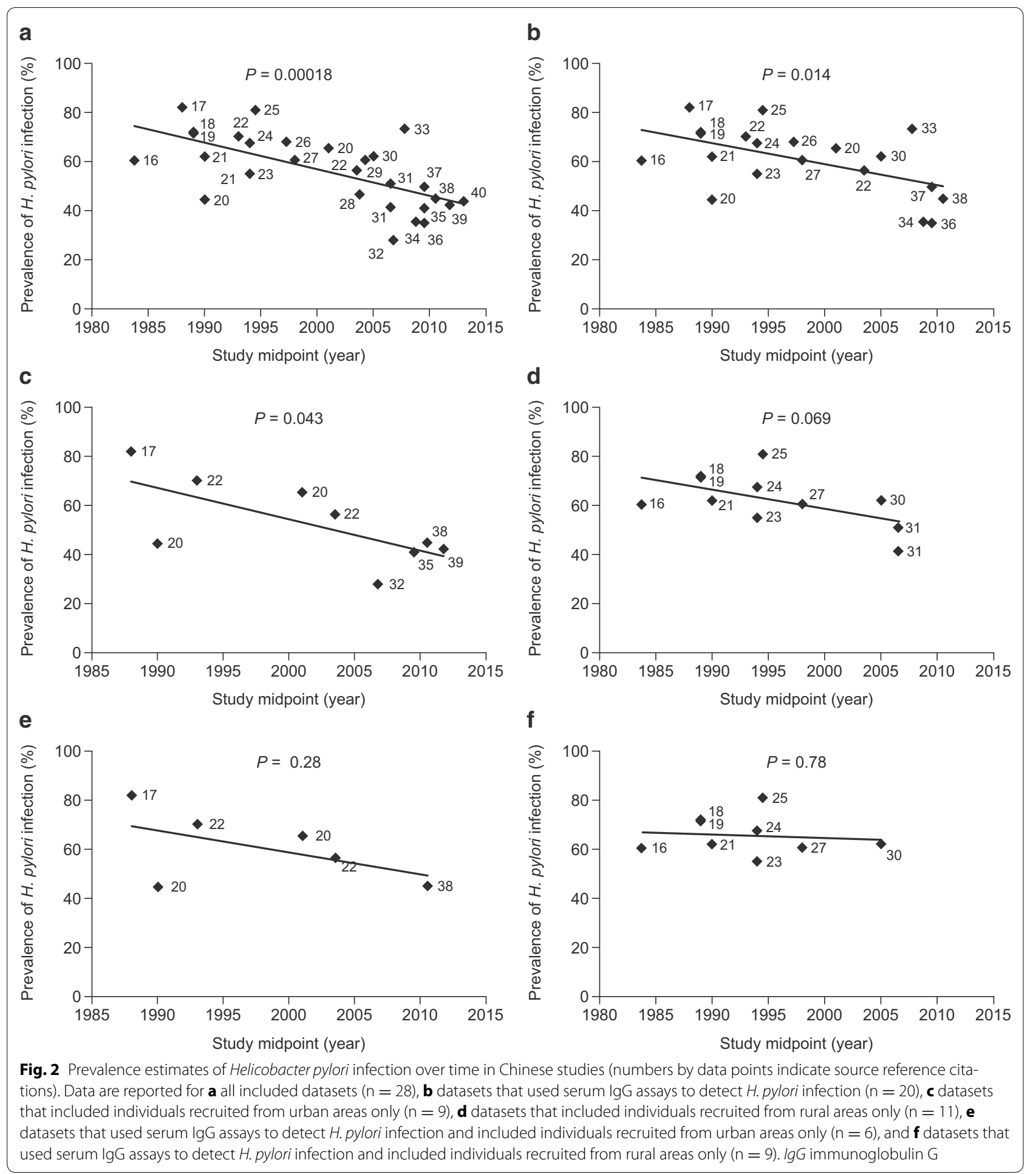

The weighted mean prevalence of $H$. pylori infection was higher for datasets that included only rural populations (66 \%; range: 41-81 \% [1983-2007]) than for those that included only urban populations (47\%; range: 28-82 \% [1988-2012]). With regard to trends over time, similar patterns of decreasing prevalence of $H$. pylori infection were observed when datasets were grouped according to whether they included only urban or rural populations (Fig. 2c, d, and Fig. 3), although the trend test was only significant for the urban analysis $(p=0.04$ 


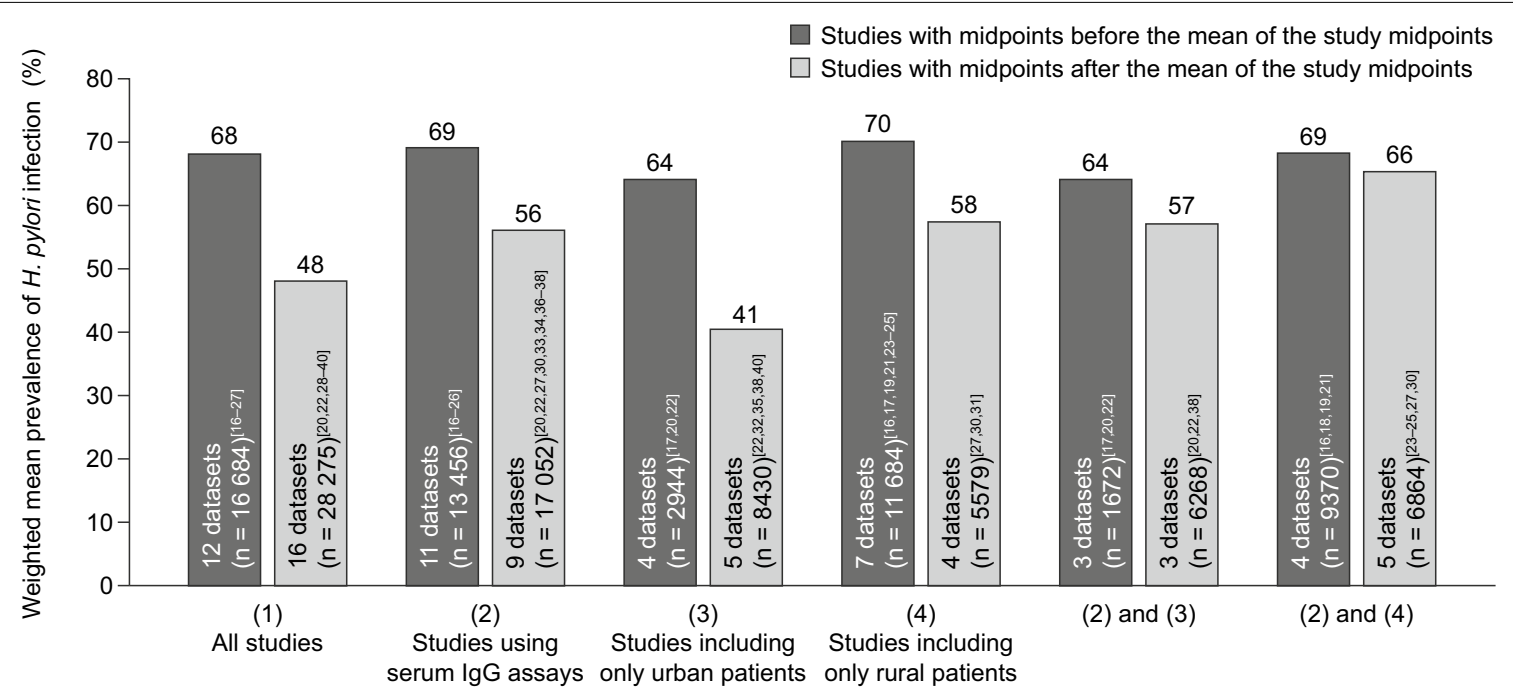

Fig. 3 Mean prevalence estimates (weighted by sample size) of Helicobacter pylori infection for Chinese datasets with study midpoints before, and after, the mean of all study midpoints, according to the assay method used and whether or not patients were living in urban or rural areas. Ig $\mathrm{G}$ immunoglobulin $\mathrm{G}$

[urban]; $p=0.07$ [rural]). The strength of the trends, however, decreased (especially for the rural analysis) and were not statistically significant ( $p=0.28$ [urban]; $p=0.78$ [rural]) when only datasets that used serum IgG assays to detect $H$. pylori infection were included (Fig. 2e, f, and Fig. 3), although this may have been because of reduced statistical power associated with the smaller available sample size, particularly for the urban serum IgG analysis.

The weighted mean prevalence of $H$. pylori infection across all datasets reported by age group was lowest among individuals aged 18-30 years (48 \%; range: 43-65\% [1990-2011]) and increased with age up to the 50-60-year age category (59\%; range: 44-73\% [1984-2007]) (Fig. 4). The weighted mean prevalence of $H$. pylori infection was higher for datasets with midpoints that fell before the mean of all study midpoints than for those with midpoints that fell after the mean of all study midpoints in every age group except patients aged 60 years and over (Fig. 4). No significant trends over time, however, were detected by regression analysis when prevalence data for each age group were plotted according to the study midpoint (data not shown).

\section{H. pylori infection prevalence over time in the USA}

The weighted mean prevalence of $H$. pylori infection across all years was $35 \%$ (range: $22-48 \%$ [1990-2006]) for the US datasets (Additional file 1: Table S1-online). There was no significant trend in terms of changes in the prevalence of $H$. pylori infection over time for the US datasets $(p=0.34)$. The weighted mean prevalence of $H$. pylori infection was lower for US datasets with midpoints that fell before the mean of all study midpoints than for those with midpoints that fell after the mean of all study midpoints (32 [41-45] vs $40 \%$ [46-50]). Of the five datasets from studies with midpoints that fell before the mean of all study midpoints, however, only two included patients over 40 years of age [42, 45], compared with all five datasets from studies with midpoints that fell after the mean of all study midpoints. Furthermore, three of the five datasets that had a study midpoint after the mean of all study midpoints did not specify the ethnic makeup of the populations assessed $[46,48,49]$.

To explore the impact of age and ethnicity on H. pylori infection further, we extracted prevalence data reported for specific ethnicities and age groups. For these analyses, the sample size exclusion criterion was not applied, hence the inclusion of one additional study by Castillo et al. 2004 [51] for the ethnicity analysis, which was conducted in 33 healthy controls (cases had dyspepsia) from Olmstead County, MN (mean age: 61 years; 58 \% women; $100 \%$ white).

Three studies conducted in the USA provided data on the prevalence of $H$. pylori infection according to different age groups [43, 45, 47]. In all of these studies, the prevalence of $H$. pylori infection was higher in older than in younger individuals (Fig. 5). There were insufficient data available to assess trends in $H$. pylori infection over time for different age groups.

Seven studies conducted in the USA provided data on the prevalence of $H$. pylori infection according to ethnicity [41-44, 47, 50,51], although one of these did not provide the sample size [44] and was thus not included in weighted mean prevalence calculations. 


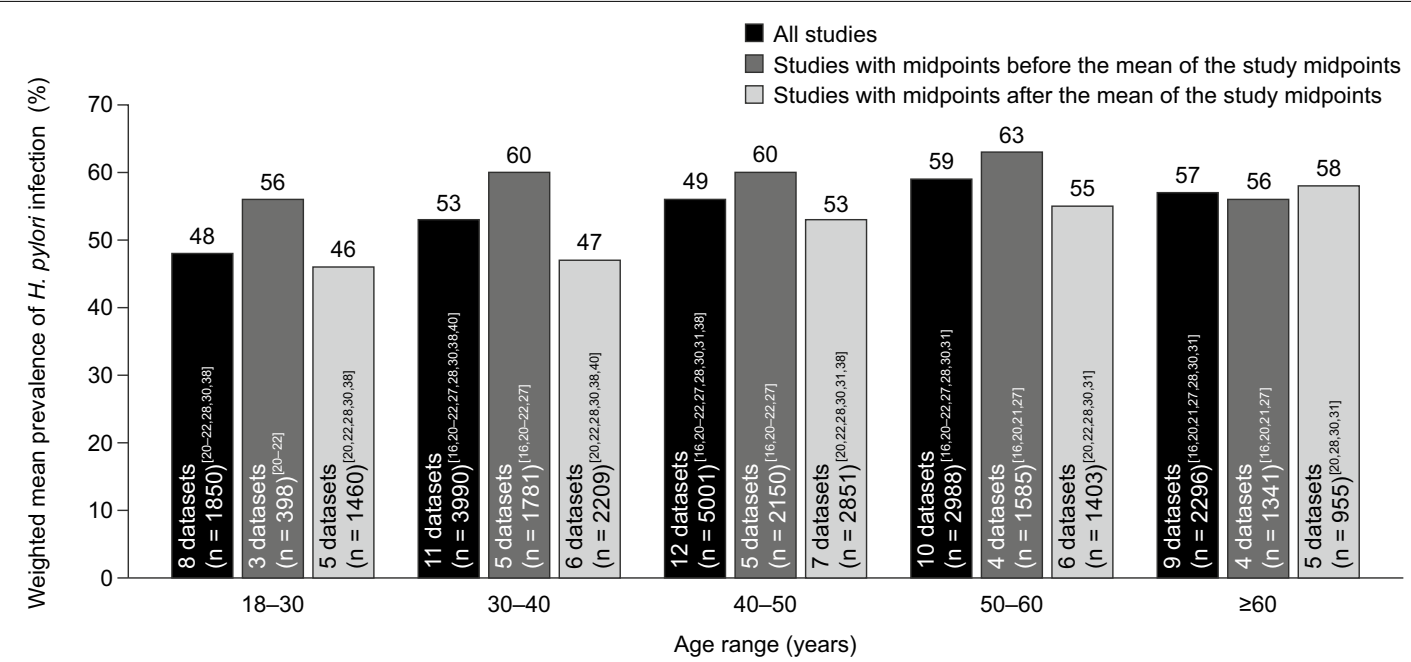

Fig. 4 Mean prevalence estimates (weighted by sample size) of Helicobacter pylori infection for Chinese datasets overall and with study midpoints before, and after, the mean of all study midpoints, according to age group

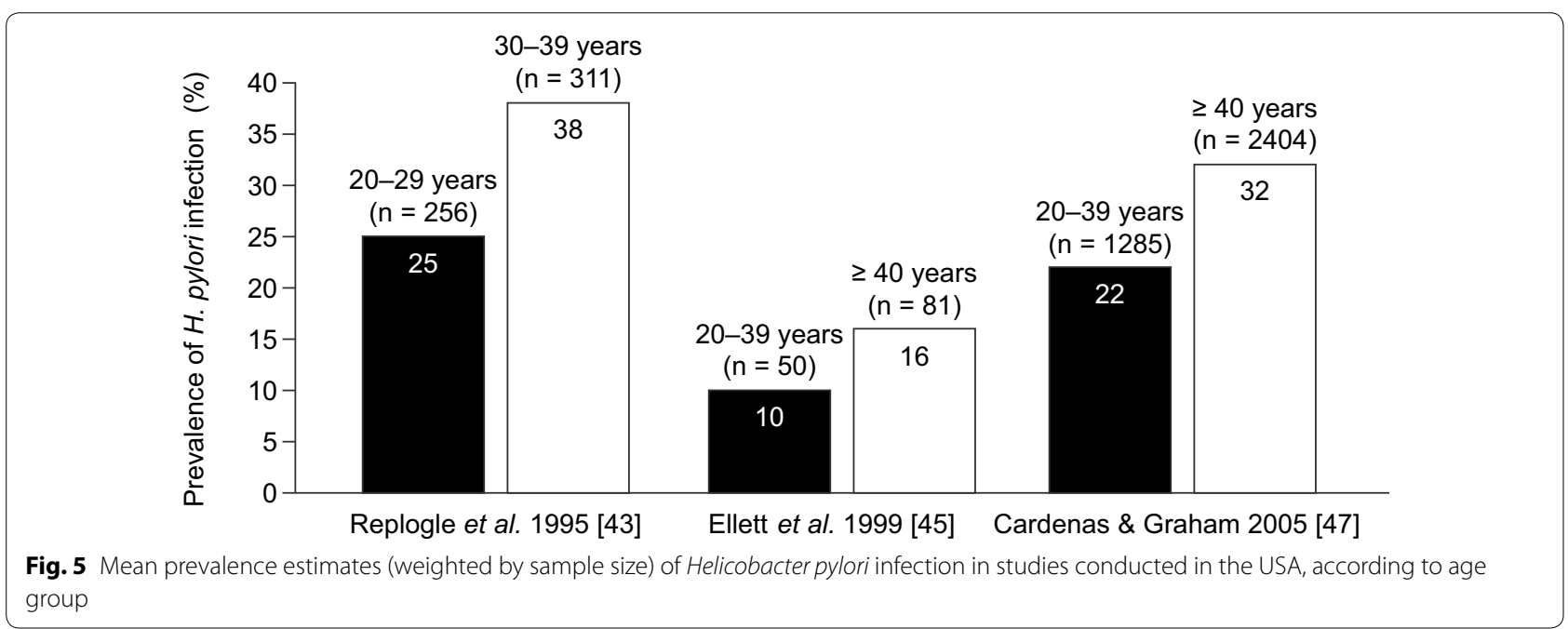

The prevalence of $H$. pylori infection was consistently higher for Hispanic and black individuals than for white individuals, and the prevalence of $H$. pylori within the different ethnicities was fairly consistent in terms of trends over time (Fig. 6), particularly for the weighted mean prevalences before and after the mean of all study midpoints, which were nearly identical (Hispanic: 61 vs $62 \%$; black: 52 vs $52 \%$; white: 24 vs $22 \%$ ). It should be noted that the weighted mean prevalence data were driven mainly by two large studies (Cardenas et al. 2005 [47] and Kruszon-Moran et al. 2005 [42]), which were both of high quality and used data during different time periods (1988-1994 and 1999-2000, respectively) from the same source, the National Health and Nutritional Examination Survey.

\section{Discussion}

Understanding country-specific trends in the prevalence of $H$. pylori is an essential component of successful future healthcare planning. We conducted a systematic literature analysis of trends in $H$. pylori infection over time in China, where rapid industrialization is probably altering the prevalence of this important organism, and the USA, where the prevalence may have stabilized. Despite variation in the characteristics of the included studies, a significant decrease in the prevalence of $H$. pylori infection over time was observed for datasets from studies conducted in China, which was consistent with a higher weighted mean prevalence of $H$. pylori infection for datasets from studies with a midpoint before, rather than after, the mean of all the study midpoints. 


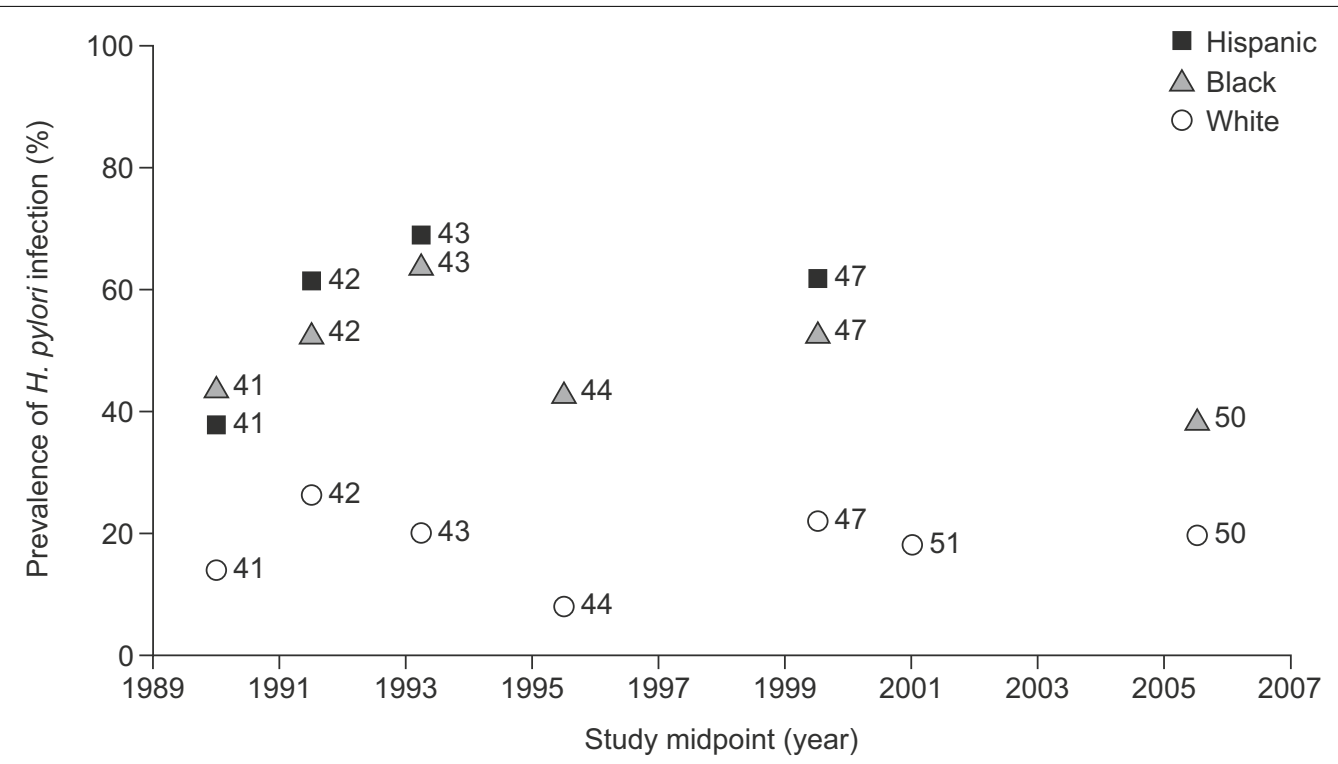

Fig. 6 Prevalence estimates of Helicobacter pylori infection over time in US studies, according to ethnicity (numbers by data points indicate source reference citations). Note: sample size was not reported for reference 44 and data from this study are therefore not included in weighted mean prevalences

It was noted that there was greater variation in methods used to detect $H$. pylori infection in datasets from more recent studies conducted in China than for older studies. Given that detection methods for H. pylori infection vary in terms of their sensitivity and specificity, and positive and negative predictive values [52], this factor could influence the observed trend in prevalence estimates over time. The trend was still significant, however, when only datasets from studies that used serum IgG assays (the most common method used to detect $H$. pylori) were included.

In addition, a higher proportion of the datasets from more recent Chinese studies were from urban rather than rural populations than for older studies. Improved living standards associated with urbanization may reduce the prevalence of $H$. pylori infection, which could influence the observed trend. Indeed, the overall weighted mean prevalence of $H$. pylori infection was much higher in samples that included individuals from rural areas only than in those that included individuals from urban areas only in our study (66 vs $47 \%$ ). However, there was also a significant trend towards a decreasing prevalence of $H$. pylori infection reported over time in studies that included only urban populations. The statistical significance of this association was lost when the analysis was further restricted to studies that used serum IgG assays, although the direction of the trend was still apparent across the few remaining datasets $(n=6)$ available for this analysis. This suggests either that the decreasing trend in $H$. pylori prevalence reported in Chinese urban studies over time is an artifact caused by an increase in those using non-serological methods to detect $H$. pylori infection, or that the significance of the trend was merely obscured owing to the reduction in sample size. The latter seems more plausible, since in the broader analysis the inclusion of only studies using serum IgG assays did not substantially visually affect the strength of the decreasing trend over time (the statistical significance decreased from $p=0.00018$ to $p=0.014$, but this might be expected given that the sample size was reduced from 28 to 20). This is consistent with recent evidence showing that differences in the sensitivity and specificity of different $H$. pylori detection methods are not that great. It is therefore questionable whether such differences would have a major impact on the observed trends in prevalence estimates over time [53].

Our study shows that urban populations in China have much lower rates of $H$. pylori infection than rural populations. The inevitable conclusion, since there has been rapid urbanization in China (possibly explaining the increase in studies conducted in urban areas over time, although this may be coincidental), is that the general prevalence of $H$. pylori infection must also have decreased. In addition, the prevalence of $H$. pylori infection may have decreased over time within urban populations. This is entirely plausible, since mean household incomes in urban areas of China have increased nearly seven-fold from 4272 yuan to 29,547 yuan since 1995 (information sourced from http://www.statista.com) and this would be expected to improve living standards 
in ways that may reduce $H$. pylori infection, such as by lowering household crowding. Indeed, similar socioeconomic factors are thought to influence differences in the prevalence of $H$. pylori infection between ethnicities in the USA [54].

Interestingly, lower weighted mean prevalence estimates were observed for newer datasets than for older datasets for all age groups except patients aged 60 years and over. These observations are based on a small number of studies, but are consistent with a role for reduced horizontal transmission of $H$. pylori owing to improved sanitation associated with urbanization. Specifically, reduced mother-to-child transmission alone is unlikely to account for reductions in the prevalence of H. pylori in older individuals, because they would have been children before the onset of significant increases in urbanization in China.

As expected, the overall prevalence of $H$. pylori infection in the US datasets was lower than in the Chinese datasets, although the prevalence of $H$. pylori infection in datasets from Chinese studies with midpoints that fell after the mean of all study midpoints was lower (48\%) than that in datasets from the US studies of black (52\%) and Hispanic (62\%) individuals. There was no significant upward or downward trend in the prevalence of $H$. pylori infection over time in the USA, although the weighted mean prevalence of $H$. pylori infection was slightly lower for US datasets with midpoints that fell before the mean of the study midpoints than for those with midpoints that fell after the mean of the study midpoints. The latter observation was probably due in part to the inclusion of older populations in the more recent US studies. This is consistent with the finding that $H$. pylori infection was more common in older patients than in younger individuals in the only three US studies reporting such data.

US data on $\mathrm{H}$. pylori infection were based on a smaller number of datasets than was available for the Chinese analysis and should thus be interpreted with caution. Nevertheless, the idea that $H$. pylori infection rates have stabilized in Hispanic, black, and white individuals in the USA is supported by two large population-based studies, which found virtually identical prevalence estimates over the span of a decade $[42,47]$. Furthermore, these data are consistent with stabilized rates of infection observed in at least one European study [55]. The continued higher prevalence of $H$. pylori infection in black and Hispanic than in white individuals probably reflects sustained socioeconomic disparities in the USA.

In terms of healthcare consequences, decreasing rates of $H$. pylori infection in China are likely to lead to a gradual decrease in peptic ulcer and gastric cancer rates; the overall proportion of peptic ulcers related to other causes will consequently increase. Conversely, the prevalence of GERD and its complications may increase in China, if it is correct that $H$. pylori infection plays a role in the low prevalence of GERD in East Asian countries compared with the West $[6,56]$. In the USA, the prevalence of peptic ulcer disease and gastric cancer may increase slightly over the coming decades, assuming that elevated H. pylori infection rates are maintained among US Hispanic populations, and that 2012 census projections (census.gov) for a doubling of the Hispanic population in the USA from 17.8 to $30.6 \%$ prove to be correct.

\section{Conclusions}

The prevalence of $H$. pylori infection appears to have decreased over time in China, while it has stabilized in the USA. Urbanization may reduce the prevalence of $H$. pylori infection.

\section{Additional file}

Additional file 1: Table S1. Characteristics of selected studies reporting the prevalence of Helicobacter pylori infection in the USA.

\section{Abbreviations}

IgG: immunoglobulin G; NS: not significant; PRISMA: Preferred Reporting Items for Systematic Reviews and Meta-Analyses; SD: standard deviation.

\section{Authors' contributions}

PN took a lead and SG and MMB both had major roles in designing the study, analyzing and interpreting the data, as well as in drafting the manuscript. All authors read and approved the final manuscript.

\section{Author details}

${ }^{1}$ AstraZeneca Gothenburg, Pepparedsleden 1, 43183 Mölndal, Sweden.

${ }^{2}$ School of Medicine, Pharmacy and Health, Durham University, Durham, UK.

${ }^{3}$ Research Evaluation Unit, Oxford PharmaGenesis Ltd, Oxford, UK.

\section{Acknowledgements}

We would like to acknowledge Stephen Sweet and Nesta Hughes, of Oxford PharmaGenesis, for their assistance with the systematic searches, and Tore Lind, formerly of AstraZeneca, for his contribution to the analysis of the data.

\section{Competing interests}

Peter Nagy and Saga Johansson are employees of AstraZeneca Gothenburg, Mölndal, Sweden. Michael Molloy-Bland is an employee of Oxford PharmaGenesis, which receives funding from AstraZeneca. This study was funded by AstraZeneca Gothenburg, Mölndal, Sweden.

Received: 21 December 2015 Accepted: 22 February 2016

Published online: 15 March 2016

\section{References}

1. Kuipers EJ. Helicobacter pylori and the risk and management of associated diseases: gastritis, ulcer disease, atrophic gastritis and gastric cancer. Aliment Pharmacol Ther. 1997;11(Suppl 1):71-88.

2. Malfertheiner P, Megraud F, O'Morain C, Bazzoli F, El-Omar E, Graham D, Hunt R, Rokkas T, Vakil N, Kuipers EJ. Current concepts in the management of Helicobacter pylori infection: the Maastricht III Consensus Report. Gut. 2007;56(6):772-81.

3. Wang C, Yuan Y, Hunt RH. The association between Helicobacter pylori infection and early gastric cancer: a meta-analysis. Am J Gastroenterol. 2007;102(8):1789-98. 
4. Selgrad M, Bornschein J, Kandulski A, Hille C, Weigt J, Roessner A, Wex T, Malfertheiner P. Helicobacter pylori but not gastrin is associated with the development of colonic neoplasms. Int J Cancer. 2014;135(5):1127-31.

5. Malfertheiner P, Selgrad M, Bornschein J. Helicobacter pylori: clinical management. Curr Opin Gastroenterol. 2012;28(6):608-14.

6. Raghunath A, Hungin AP, Wooff D, Childs S. Prevalence of Helicobacter pylori in patients with gastro-oesophageal reflux disease: systematic review. BMJ. 2003;326(7392):737

7. Park $\mathrm{CH}$, Kim KO, Baek IH, Choi MH, Jang HJ, Kae SH, Kim JB, Baik GH, Shin WG, Kim KH, et al. Differences in the risk factors of reflux esophagitis according to age in Korea. Dis Esophagus. 2014;27(2):116-21.

8. Xie T, Cui X, Zheng H, Chen D, He L, Jiang B. Meta-analysis: eradication of Helicobacter pylori infection is associated with the development of endoscopic gastroesophageal reflux disease. Eur J Gastroenterol Hepatol. 2013;25(10):1195-205.

9. Grande M, Lisi G, De Sanctis F, Grande S, Esser A, Campanelli M, Balassone $\checkmark$, Milito G, Villa M. Does a relationship still exist between gastroesophageal reflux and Helicobacter pylori in patients with reflux symptoms? World J Surg Oncol. 2014;12:375.

10. Lee YY, Mahendra Raj S, Graham DY. Helicobacter pylori infection-a boon or a bane: lessons from studies in a low-prevalence population. Helicobacter. 2013;18(5):338-46.

11. Rubenstein $J H$, Inadomi JM, Scheiman J, Schoenfeld P, Appelman H, Zhang M, Metko V, Kao JY. Association between Helicobacter pylori and Barrett's esophagus, erosive esophagitis, and gastroesophageal reflux symptoms. Clin Gastroenterol Hepatol. 2014;12(2):239-45.

12. Yokota SI, Konno M, Fujiwara SI, Toita N, Takahashi M, Yamamoto S, Ogasawara N, Shiraishi T. Intrafamilial, preferentially mother-to-child and intraspousal, Helicobacter pylori infection in Japan determined by mutilocus sequence typing and random amplified polymorphic DNA fingerprinting. Helicobacter. 2015;20(5):334-42.

13. Kamada T, Haruma K, Ito M, Inoue K, Manabe N, Matsumoto H, Kusunoki H, Hata J, Yoshihara M, Sumii K, et al. Time trends in Helicobacter pylori infection and atrophic gastritis over 40 years in Japan. Helicobacter. 2015;20(3):192-8.

14. Graham DY. History of Helicobacter pylori, duodenal ulcer, gastric ulcer and gastric cancer. World J Gastroenterol. 2014;20(18):5191-204.

15. Moher D, Liberati A, Tetzlaff J, Altman DG, PRISMA Group. Preferred reporting items for systematic reviews and meta-analyses: the PRISMA statement. BMJ. 2009;339:b2535.

16. Forman D, Sitas F, Newell DG, Stacey AR, Boreham J, Peto R, Campbell TC, Li J, Chen J. Geographic association of Helicobacter pylori antibody prevalence and gastric cancer mortality in rural China. Int J Cancer. 1990;46(4):608-11.

17. Yuan JM, Yu MC, Xu WW, Cockburn M, Gao YT, Ross RK. Helicobacter pylori infection and risk of gastric cancer in Shanghai, China: updated results based upon a locally developed and validated assay and further followup of the cohort. Cancer Epidemiol Biomarkers Prev. 1999;8(7):621-4.

18. Zhang L, Blot WJ, You WC, Chang YS, Kneller RW, Jin ML, Li JY, Zhao L, Liu WD, Zhang JS, et al. Helicobacter pylori antibodies in relation to precancerous gastric lesions in a high-risk Chinese population. Cancer Epidemiol Biomarkers Prev. 1996;5(8):627-30.

19. Wang $X$, Terry $P$, Yan H. Stomach cancer in 67 Chinese counties: evidence of interaction between salt consumption and helicobacter pylori infection. Asia Pac J Clin Nutr. 2008;17(4):644-50.

20. Chen SL, Xiao SD. Seroepidemiological comparison of Helicobacter pylori infection rates in Shanghai urban districts in 1990 and 2001. Chin J Digestive Dis. 2003;4(1):40-4.

21. Chen S, Xiao S, Liu W, Xu W, Pan Y. Comparison of seroepidemiology of Helicobacter pylori in Shanghai urban area during 1990 and 2001. Chin J Gastroenterol. 2002;7(3):146-8.

22. Chen J, Bu XL, Wang QY, Hu PJ, Chen MH. Decreasing seroprevalence of Helicobacter pylori infection during 1993-2003 in Guangzhou, southern China. Helicobacter. 2007;12(2):164-9.

23. You WC, Zhang L, Gail MH, Ma JL, Chang YS, Blot WJ, Li JY, Zhao CL, Liu WD, Li HQ, et al. Helicobacter pylori infection, garlic intake and precancerous lesions in a Chinese population at low risk of gastric cancer. Int J Epidemiol. 1998;27(6):941-4

24. Ma JL, You WC, Gail MH, Zhang L, Blot WJ, Chang YS, Jiang J, Liu WD, Hu $Y R$, Brown LM, et al. Helicobacter pylori infection and mode of transmission in a population at high risk of stomach cancer. Int J Epidemiol. 1998:27(4):570-3.
25. Wong BC, Lam SK, Ching CK, Hu WH, Ong LY, Chen BW, Gao Z, Chen JS, Jiang XW, Hou XH, et al. Seroprevalence of cytotoxin-associated gene a positive Helicobacter pylori strains in Changle, an area with very high prevalence of gastric cancer in south China. Aliment Pharmacol Ther. 1999;13(10):1295-302.

26. Cai L, Yu SZ, Zhang ZF. Helicobacter pylori infection and risk of gastric cancer in Changle County, Fujian province, China. World J Gastroenterol. 2000;6(3):374-6.

27. Brown LM, Thomas TL, Ma JL, Chang YS, You WC, Liu WD, Zhang L, Gail $\mathrm{MH}$. Helicobacter pylori infection in rural China: exposure to domestic animals during childhood and adulthood. Scand J Infect Dis. 2001;33(9):686-91.

28. Cheng H, Hu F, Zhang L, Yang G, Ma J, Hu J, Wang W, Gao W, Dong X Prevalence of Helicobacter pylori infection and identification of risk factors in rural and urban Beijing, China. Helicobacter. 2009;14(2):128-33.

29. Chen SJ, Wang $\sqcup$, Zhu Q, Cai JT, Chen T, Si JM. Effect of H. pylori infection and its eradication on hyperammo-nemia and hepatic encephalopathy in cirrhotic patients. World J Gastroenterol. 2008;14(12):1914-8.

30. Shi R, Xu S, Zhang H, Ding Y, Sun G, Huang X, Chen X, Li X, Yan Z, Zhang G. Prevalence and risk factors for Helicobacter pylori infection in Chinese populations. Helicobacter. 2008;13(2):157-65.

31. Zhang DH, Zhou LY, Lin SR, Ding SG, Huang YH, Gu F, Zhang L, Li Y, Cui RL, Meng LM, et al. Recent changes in the prevalence of Helicobacter pylori infection among children and adults in high-or low-incidence regions of gastric cancer in China. Chin Med J (Engl). 2009;122(15):1759-63.

32. Peng S, Cui Y, Xiao YL, Xiong LS, Hu PJ, Li CJ, Chen MH. Prevalence of erosive esophagitis and Barrett's esophagus in the adult Chinese population. Endoscopy. 2009;41(12):1011-7.

33. Li Z, Zou D, Ma X, Chen J, Shi X, Gong Y, Man X, Gao L, Zhao Y, Wang R, et al. Epidemiology of peptic ulcer disease: endoscopic results of the systematic investigation of gastrointestinal disease in China. Am J Gastroenterol. 2010;105(12):2570-7.

34. Wang MY, Yue JY, Zhang YX, Liu XD, Gao XZ. Helicobacter pylori infection in asymptomatic HBV carriers, alcohol users and normal adult population in Shandong province, China. Clin Res Hepatol Gastroenterol. 2011;35(8-9):560-2

35. Xia P, Ma MF, Wang W. Status of Helicobacter pylori infection among migrant workers in Shijiazhuang, China. Asian Pac J Cancer Prev. 2012;13(4):1167-70.

36. Wang $X Q$, Yan $H$, Terry PD, Wang JS, Cheng L, Wu WA, Hu SK. Interaction between dietary factors and Helicobacter pylori infection in noncardia gastric cancer: a population-based case-control study in China. J Am Coll Nutr. 2012;31(5):375-84.

37. Jiang J, Jia ZF, Kong F, Jin MS, Wang YP, Tian S, Suo J, Cao X. Association of polymorphism of PTPN 11 encoding SHP-2 with gastric atrophy but not gastric cancer in Helicobacter pylori seropositive Chinese population. BMC Gastroenterol. 2012;12:89.

38. Hu D, Shao J, Wang L, Zheng H, Xu Y, Song G, Liu Q. Prevalence and risk factors of Helicobacter pylori infection in Chinese maritime workers. Ann Hum Biol. 2013;40(6):472-6.

39. Cao HL, Qu R, Zhang ZH, Kong XY, Wang S, Jiang K, Wang BM. Sporadic fundic gland polyps are not associated with proton pump inhibitors therapy but negatively correlate with Helicobacter pylori infection in China. Chin Med J. 2014;127(7):1239-43.

40. Xu C, Yan M, Sun Y, Joo J, Wan X, Yu C, Wang Q, Shen C, Chen P, Li Y, et al. Prevalence of Helicobacter pylori infection and its relation with body mass index in a Chinese population. Helicobacter. 2014;19(6):437-42.

41. Smoak BL, Kelley PW, Taylor DN. Seroprevalence of Helicobacter pylori infections in a cohort of US Army recruits. Am J Epidemiol. 1994;139(5):513-9.

42. Kruszon-Moran D, McQuillan GM. Seroprevalence of six infectious diseases among adults in the United States by race/ethnicity: data from the third National Health and Nutrition Examination Survey, 1988-94. Adv Data. 2005;352:1-9.

43. Replogle ML, Glaser SL, Hiatt RA, Parsonnet J. Biologic sex as a risk factor for Helicobacter pylori infection in healthy young adults. Am J Epidemiol. 1995;142(8):856-63.

44. Malaty HM, El-Kasabany A, Graham DY, Miller CC, Reddy SG, Srinivasan SR, Yamaoka Y, Berenson GS. Age at acquisition of Helicobacter pylori infection: a follow-up study from infancy to adulthood. Lancet. 2002;359(9310):931-5. 
45. Ellett ML, Lou Q, Chong SK. Prevalence of immunoglobulin G to Helicobacter pylori among endoscopy nurses/technicians. Gastroenterol Nurs. 1999;22(1):3-6.

46. Bunch TJ, Day JD, Anderson JL, Horne BD, Muhlestein JB, Crandall BG, Weiss JP, Lappe DL, Asirvatham SJ. Frequency of Helicobacter pylori seropositivity and C-reactive protein increase in atrial fibrillation in patients undergoing coronary angiography. Am J Cardiol. 2008;101(6):848-51.

47. Cardenas VM, Graham DY. Smoking and Helicobacter pylori infection in a sample of US adults. Epidemiology. 2005;16(4):586-90.

48. Lutsey PL, Pankow JS, Bertoni AG, Szklo M, Folsom AR. Serological evidence of infections and Type 2 diabetes: the multiethnic study of atherosclerosis. Diabet Med. 2009;26(2):149-52.

49. Erim T, Cruz-Correa MR, Szomstein S, Velis E, Rosenthal R. Prevalence of Helicobacter pylori seropositivity among patients undergoing bariatric surgery: a preliminary study. World J Surg. 2008;32(9):2021-5.

50. Papasavas PK, Gagne DJ, Donnelly PE, Salgado J, Urbandt JE, Burton KK, Caushaj PF. Prevalence of Helicobacter pylori infection and value of preoperative testing and treatment in patients undergoing laparoscopic Roux-en-Y gastric bypass. Surg Obes Relat Dis. 2008;4(3):383-8.

51. Castillo EJ, Camilleri M, Locke GR, Burton DD, Stephens DA, Geno DM, Zinsmeister AR. A community-based, controlled study of the epidemiology and pathophysiology of dyspepsia. Clin Gastroenterol Hepatol. 2004;2(11):985-96.
52. Kazemi S, Tavakkoli H, Habizadeh MR, Emami MH. Diagnostic values of Helicobacter pylori diagnostic tests: stool antigen test, urea breath test, rapid urease test, serology and histology. J Res Med Sci. 2011;16(9):1097-104.

53. Choi J, Kim CH, Kim D, Chung SJ, Song JH, Kang JM, Yang Jl, Park MJ, Kim YS, Yim JY, et al. Prospective evaluation of a new stool antigen test for the detection of Helicobacter pylori, in comparison with histology, rapid urease test, (13)C-urea breath test, and serology. Gastroenterol Hepatol. 2011;26(6):1053-9.

54. Tenover FC, McGowan JE. Acute bacterial infections. In: Evans AS editor. Bacterial infections of humans: epidemiology and control. 3rd ed. Springer; 2013.p 342.

55. den Hoed CM, Vila AJ, Holster IL, Perez-Perez GI, Blaser MJ, de Jongste JC, Kuipers EJ. Helicobacter pylori and the birth cohort effect: evidence for stabilized colonization rates in childhood. Helicobacter. 2011;16(5):405-9.

56. Wong BC, Kinoshita Y. Systematic review on epidemiology of gastroesophageal reflux disease in Asia. Clin Gastroenterol Hepatol. 2006:4(4):398-407.

\section{Submit your next manuscript to BioMed Central and we will help you at every step:}

- We accept pre-submission inquiries

- Our selector tool helps you to find the most relevant journal

- We provide round the clock customer support

- Convenient online submission

- Thorough peer review

- Inclusion in PubMed and all major indexing services

- Maximum visibility for your research

Submit your manuscript at www.biomedcentral.com/submit
() Biomed Central 